COMUNI CAÇÃO DE PESQUISA

\title{
Ajustamento de alunos ingressantes ao ensino superior: o papel do comportamento exploratório vocacional
}

\section{Adjustament of begginers college students: the role of vocational exploratory behavior}

\section{Eliane Gerk*}

Universidade Católica de Petrópolis, Petrópolis, RJ, Brasil

José Augusto Rento Cardoso**

Universidade Católica de Petrópolis, Petrópolis, RJ, Brasil

\section{Luiza Martins Krafft**}

Universidade Católica de Petrópolis, Petrópolis, RJ, Brasil

\section{I ntrodução}

O acesso ao Ensino Superior está sendo cada vez mais amplo e por um público cada vez mais socialmente heterogêneo, deixando de ser um "ensino de elites" para ser um "ensino de massas". No Brasil, a procura deste nível de ensino tem ocorrido por um número cada vez maior e mais diversificado de jovens que concluem o ensino médio. Entretanto existe escassez de programas e de serviços de apoio à transição. Acresce-se a isto os elevados custos pessoais, familiares e sociais que a frequência a esse nível de ensino acarreta. Tais fatores aumentam significativamente a pressão que esses jovens sofrem relativamente à obtenção de sucesso. Existe um interesse crescente pelo desenvolvimento de estudos que procurem compreender a natureza do ajustamento desta população ao Ensino Superior, assim como do seu êxito e dos fatores que o facilitam ou o inibem.

Entre as múltiplas e complexas tarefas com as quais os jovens são confrontados nesta transição educativa, Almeida, Soares e Ferreira (1999) e Soares (1998) apontam para tarefas associadas a quatro domínios principais: acadêmico, social, pessoal e vocacional.

No âmbito do desenvolvimento vocacional, existe um tipo de comportamento que desempenha um papel muito importante, por possibilitar as informações essenciais para a formação do auto conceito, tanto geral, como vocacional. Trata-se do comportamento exploratório. Tal conceito encontra sua origem na obra de Jordaan (1963; apud

\begin{tabular}{|l|l|l|l|l|l|}
\hline Estudos e Pesquisas em Psicologia & Rio de Janeiro & v. 11 & n. 2 & p. 719-724 & 2011 \\
\hline
\end{tabular}


TEIXEIRA; BARDAGI; HUTZ, 2007) no campo da Psicologia Experimental e designa um comportamento que possibilita o acesso a informações e facilita o aprendizado. Trata-se de um comportamento de solução de problemas, proposital e intencional. O objetivo de tal comportamento é reunir informações sobre si mesmo e seu ambiente e verificar ou encontrar recursos para construção de uma hipótese que ajude o indivíduo a escolher, preparar, assumir, ajustar-se ou progredir em seu campo de trabalho.

Dentro do comportamento exploratório duas dimensões são de especial interesse: a exploração de si e a exploração do ambiente. A exploração de si envolve, principalmente, comportamentos de busca por conhecer suas próprias capacidades e reflexões a cerca de si, suas habilidades, personalidade, valores e influências com respeito à escolha vocacional (TEIXEIRA; BARDAGI; HUTZ, 2007).

A exploração do ambiente envolve comportamentos de busca por conhecimento sobre a realidade do trabalho (carreira) e informações importantes sobre determinada área de conhecimento. Ela também resulta em um maior conhecimento das alternativas educacionais e profissionais (TEIXEIRA et al. 2007)

Buscando aferir empiricamente este conceito, Teixeira, Bardagi e Hutz (op cit) desenvolveram um instrumento voltado para a população universitária, com objetivo de avaliar essas duas grandes dimensões do comportamento exploratório vocacional: a exploração de si e a exploração do ambiente.

\section{Hipóteses}

Partiu-se da hipótese que os estudantes de psicologia apresentariam maior média de comportamentos voltados para a exploração de si, do que os outros estudantes dos cursos de direito e engenharia, em detrimento da exploração do ambiente. Acreditou-se que os ingressantes, por terem escolhido psicologia, têm seu interesse voltado para aspectos da psique humana.

\section{Metodologia}

Participantes: Participaram do estudo 42 estudantes ingressantes no primeiro período dos cursos mencionados, sendo 10 de Psicologia, 17 de Direito e 15 de Engenharia, sendo 25 mulheres e 17 homens, com idade média de 22,3 anos. 
Tabela 1: Distribuição dos participantes por sexo

\begin{tabular}{l|c|c|c|} 
& No DE HOMENS & No DE MULHERES & IDADE MÉDIA \\
\hline PSICOLOGIA & 1 & 9 & 26,5 \\
\hline DIREITO & 6 & 11 & 22,2 \\
\hline ENGENHARIA & 10 & 5 & 19,6 \\
\hline
\end{tabular}

Como ingressantes entendemos aqueles alunos que nunca haviam iniciado um curso superior, ou seja, que pela primeira vez estavam entrando um uma Universidade como estudantes.

Instrumento: Foi aplicada a Escala de Exploração Vocacional - EEV (TEIXEIRA; BARDAG; HUTZ, 2007). Esta escala objetiva avaliar duas grandes dimensões do comportamento vocacional indicadas na literatura: a exploração de si, que resulta em maior auto conhecimento, e a exploração do ambiente, que resulta em maior conhecimento das alternativas educacionais e profissionais do mundo do trabalho. A escala é composta por 24 afirmações, sendo 10 referentes à exploração de si e 14 referentes à exploração do ambiente, sendo a mesma uma escala Likert de cinco alternativas.

\section{Procedimentos}

Foram obtidas as assinaturas do Termo de Consentimento Livre e Esclarecido nas três turmas que participaram. A seguir foram aplicadas as Escalas, com duração de aproximadamente 20 minutos.

\section{Resultados e Discussão}

Os resultados obtidos estão apresentados na Tabela 2.

Tabela 2: Resultados dos cursos.

\begin{tabular}{|c|c|c|c|c|}
\hline & \multicolumn{2}{c|}{$\begin{array}{c}\text { SUB ESCALA EXPLORAÇÃO DO } \\
\text { AMBIENTE }\end{array}$} & \multicolumn{2}{c|}{$\begin{array}{c}\text { SUB ESCALA EXPLORAÇÃO } \\
\text { DE SI }\end{array}$} \\
\hline CURSO & MÉDIA & DESVIO P. & MÉDIA & DESVIO P. \\
\hline PSICOLOGIA & 45,40 & 9,91 & 36,30 & 7,13 \\
\hline DIREITO & 49,00 & 8,65 & 38,29 & 9,24 \\
\hline ENGENHARIA & 46,33 & 10,68 & 31,33 & 8,53 \\
\hline
\end{tabular}

Tabela 3: Resultado por gênero:

\begin{tabular}{|l|c|c|} 
& HOMENS & MULHERES \\
\hline EXPLORAÇÃO DE SI & 35,41 & 38,88 \\
\hline EXPLORAÇÃO DO AMBIENTE & 43,41 & 49,88 \\
\hline
\end{tabular}


A análise dos resultados demonstra que a média da sub-escala exploração do ambiente é maior em todos os cursos em comparação a sub-escala exploração de si, uma vez que o nível de significância encontrado para o curso de psicologia no teste de Student foi 0,00145, para o curso de engenharia foi 0,00025 e para o curso de direito foi 0,00001 . Com referência ao gênero observou-se que as mulheres obtiveram escores mais altos em ambas as escalas. O curso de Psicologia foi o que apresentou a menor média tanto na sub-escala exploração do ambiente, como na exploração de si. O curso de Direito apresentou a maior pontuação em ambas as escalas.

\section{Conclusões}

No que se refere ao curso de Psicologia, a hipótese de que a média da sub-escala exploração de si seria maior do que a exploração do ambiente não foi confirmada, assim como também foi rejeitada a hipótese de que este curso apresentaria o resultado maior na sub-escala exploração de si, quando comparado com os outros dois cursos. Pode-se cogitar que os estudantes de psicologia estejam muito mais interessados em compreender o mundo e as pessoas do que a si mesmo.

Quanto à superioridade de resultados na sub-escala exploração do ambiente do que na exploração de si em todos os cursos, pode-se considerar que: 1) a sociedade atual não incentiva a busca pelo autoconhecimento. A grande quantidade de estímulos e informações, o ritmo acelerado do estilo de vida, a estimulação à obtenção de prazeres imediatos criando uma cultura hedonista e superficial são fatores que contribuem para uma postura menos reflexiva a respeito de si mesmo; 2) por serem estudantes do primeiro período e não terem cursado um outro curso superior anteriormente, tem seu interesse voltado mais para a exploração do ambiente, buscando um melhor ajustamento ao meio em detrimento da exploração de si.

Em continuidade a esta pesquisa, pretende-se aplicar a escala de Exploração Vocacional nos estudantes dos períodos subsequentes dos mesmos cursos, assim como de outros cursos da mesma Universidade. Buscar-se-á, assim, verificar se o comportamento exploratório vocacional se modifica a medida que o estudante avança em seus estudos.

\section{Referências Bibliográficas}

ALMEIDA, L. S.; SOARES, A. P. C.; FERREIRA, J. A. G. Adaptação, rendimento e desenvolvimento dos estudantes no ensino superior: Construção/validação do Questionário de Vivências 
Académicas. Relatórios de Investigação. Braga: Universidade do Minho, Centro de Estudos em Educação e Psicologia, 1999.

AQUINO, S. M. C. Insucesso E Evasão No Ensino Superior: I mpacto Das Vivências Acadêmicas Em Alunos Do 1을 Ano Da Universidade Federal De Sergipe. 2008. Tese (Doutorado) - Universidade Federal do Ceará, Fortaleza.

FARIA, L. Concepções pessoais de competência: promover a aprendizagem e o desempenho dos alunos. Revista I novação, Lisboa v. 11, p. 50-55, 1998.

FERREIRA, J. A. As teorias interaccionistas e o desenvolvimento do estudante do Ensino Superior. Revista Portuguesa de Pedagogia, Coimbra, v. 25, p. 91-105, 1991.

FERREIRA, J. A.; HOOD, A. Para a compreensão do desenvolvimento psicossocial do estudante universitário. Revista Portuguesa de Pedagogia, Coimbra, v. 24, p. 391-406, 1990.

GERK, E.; CUNHA, S. M. As habilidades sociais na adaptação de estudantes ao ensino superior. In: BANDEIRA, M.; DEL PRETTE, $Z$. A. P. A. Estudos sobre Habilidades Sociais e Relacionamento Interpessoal. São Paulo: Casa do Psicólogo. 2006.

MAGALHAES, M.; REDIVO, A. Re-opção de curso e maturidade vocacional. Rev. ABOP [online], São Paulo, vol.2, n.2 pp. 7-28, 1998 .

SELIGMAN, M. E. P. Aprenda a Ser Otimista. Rio de Janeiro: Nova Era, 20 ed., 2005.

SOARES, A. P. Desenvolvimento vocacional de jovens adultos: a exploração, a indecisão e o ajustamento vocacional em estudantes universitários. Dissertação de Mestrado. Braga: Universidade do Minho. 1998.

SPARTA, M.; BARDAGI, M. P.; ANDRADE, A. Exploração vocacional e informação profissional percebida em estudantes carentes. Aletheia [online]. Canoas, n. 22 p. 79-88, 2005.

TEIXEIRA, M. A. P.; BARGAGI, M. P.; HUTZ, C. S. Escala de Exploração Vocacional (EEV) para Universitários. Psicologia em Estudo, v. 12, n. 1, p. 195-202. Maringá, 2007.

TEIXEIRA, M. A. P.; CASTRO, D. G.; PICCOLO, L. R. Adaptação à Universidade em Estudantes Universitários: um estudo correlacional. I nteração em Psicologia, v. 11, n. 2, p. 211-220, Curitiba, 2007.

\section{Endereço para correspondência}

Eliane Gerk

Avenida General Felicíssimo Cardoso 835, bloco 1,apto 1707, Barra da Tijuca, CEP 22631-360, Rio de Janeiro - RJ, Brasil

Endereço eletrônico: elianegerk@gmail.com 
Eliane Gerk, José Augusto Rento Cardoso, Luiza Martins Krafft Ajustamento de alunos ingressantes ao ensino superior

José Augusto Rento Cardoso

Rua Paulino Afonso, Vila São J osé, 26, Centro, CEP 25680-003, Petrópolis - RJ, Brasil

Endereço eletrônico: j_rento@yahoo.com.br

Luiza Martins Krafft

Rua do Imperador, 880/604, Centro, CEP 25680-000, Petrópolis - RJ, Brasil

Endereço eletrônico: lui-mk@hotmail.com

Recebido em: 23/02/2011

Aceito para publicação em: 03/03/2011

Acompanhamento do processo editorial: Adriana Benevides Soares

\section{Notas}

* Doutora em Psicologia pela Fundação Getúlio Vargas - FGV, Rio de Janeiro.

* Graduando em Psicologia. 